\title{
TANDEM-X DEM CALIBRATION: CORRECTION OF SYSTEMATIC DEM ERRORS BY BLOCK ADJUSTMENT
}

\author{
Astrid Gruber, Birgit Wessel, Martin Huber \\ German Remote Sensing Data Center, German Aerospace Center (DLR), Oberpfaffenhofen, \\ 82234 Wessling, Germany \\ Email: [Astrid.Gruber, Birgit.Wessel, Martin.Huber]@dlr.de
}

\begin{abstract}
This paper gives an overview of the DEM adjustment within the TanDEM-X mission. The DEM adjustment estimates residual, systematic height offsets and deformations of each single interferometric DEM acquisition. The challenge of calibrating the TanDEM-X DEMs lies in the magnitude of the systematic errors: these errors are in the same order like the random error of about $2 \mathrm{~m}$. For the estimation of the corrections a least-squares adjustment of adjacent, overlapping interferometric DEMs over a certain earth region is described in this paper. Adjustment results on simulated DEM data are shown to validate the approach. The tests are carried out for different dense ground control point configurations. Further the improvements by a combined adjustment of the two coverages are demonstrated.
\end{abstract}

Index Terms-TanDEM-X, InSAR, block adjustment, DEM/DTM, calibration

\section{INTRODUCTION}

The goal of the German spaceborne SAR interferometry mission TanDEM-X (TerraSAR add-on for Digital Elevation Measurements) is the generation of a global DEM. It shall be available four years after the start of the TanDEM-X satellite [2]. The height accuracy requirements of $10 \mathrm{~m}$ absolute vertical error and $2 \mathrm{~m}$ relative vertical error are very ambitious.

The designed mission plan foresees that all land surfaces will be covered at least twice with different heights of ambiguity to minimize the height error by averaging DEM acquisitions and to facilitate the phase unwrapping by multibaseline methods. Each interferometeric DEM acquisition still consists remaining systematic height errors like offset and tilts. In order to correct these systematic errors a leastsquares adjustment of adjacent, overlapping DEM acquisitions is set up.

The DEM adjustment is part of the operational "DEM Mosaicking and Calibration Processor" [3], which will adjust the interferometric DEMs globally to produce the TanDEM-X DEM product.

In order to estimate and correct the remaining systematic errors, a functional model has been set up. This allows the design of a subsequent DEM block adjustment (Ch. 2). In Ch. 3 the block adjustment will be evaluated by a simulated test site.

\section{DEM BLOCK ADJUSTMENT}

The goal of the DEM adjustment is to estimate systematic height errors to fulfil the required height accuracies. In this chapter the design of the DEM block adjustment is described.

The main sources of residual systematic height errors in bi-static interferometric DEMs are inaccuracies in the baseline determination. Baseline inaccuracies and other systematic instrument errors introduce mainly low frequency errors in terms of the data take length. Baseline errors parallel to the line of sight cause a vertical displacement and a tilt of the DEM.

The systematic errors can be approximately expressed by a third order polynomial for one TanDEM-X DEM acquisition:

$g_{I}(r g, a z)=a_{I}+b_{I} r g+c_{I} a z+d_{I} r g a z+e_{I} a z^{2}+f_{I} a z^{3}$,

where $\quad \mathrm{a}, \mathrm{b}, \mathrm{c}, \mathrm{d}, \mathrm{e}, \mathrm{f}=$ unknown error parameters

$\mathrm{I}=$ index of the DEM acquisition

$\mathrm{rg}, \mathrm{az}=$ image coordinates (range, azimuth)

This error description was found through a statistical study. Main influences are the height offset $a$ and slopes in range $b$ and azimuth $c$ that cause errors above $0.5 \mathrm{~m}$. The influence of the torsion $d$ between range and azimuth and second $e$ and third order $f$ errors in azimuth are expected to be much smaller. Above this, a random phase that can be regarded as noise is present. A noise level slightly above $2 \mathrm{~m}$ is expected for one interferometric TanDEM-X DEM acquisition. 
For the block adjustment it is assumed that each DEM acquisition is solely distorted by the errors expressed in Eq. 1. The positioning of the DEM acquisitions is assumed to be correct within the limit of $10 \mathrm{~m}$ absolute horizontal accuracy. The challenge of calibrating the TanDEM-X DEM lies in the magnitude of the systematic errors: these errors are in the same order like the random error of about $2 \mathrm{~m}$.

\subsection{Adjustment set-up}

Prerequisite for the adjustment is the availability of suitable ground control points to assess the absolute height error offset with respect to WGS84. Also reliable tie-points, i.e. identical points in overlapping DEM areas, are needed to fulfil the strong relative vertical requirement of $2 \mathrm{~m}$.

\subsubsection{Ground control and tie-points}

As absolute height reference ICESat (Ice, Cloud, and land Elevation Satellite) data will be the main height reference source for TanDEM-X. The ICESat space-borne laser altimeter data provide globally distributed, accurate height information as well as evaluation and classification information for each measurement point [4]. Therefore, ICESat provides a good global coverage for hooking in the DEM with a point distance of $270 \mathrm{~m}$ in along-track and a point distance of $30 \mathrm{~km}$ in across track. The accuracy could be proven to be less than $2 \mathrm{~m}$ for selected measurements [1].

Tie-points are identical points in at least two overlapping DEMs. A good distribution and a high reliability regarding the height error should be given. The DEM acquisition length is about 500 to $1000 \mathrm{~km}$ in azimuth and about $30 \mathrm{~km}$ in range. The overlap area to adjacent across-track DEMs is at least $3 \mathrm{~km}$. To derive a good tiepoint distribution the tie-points are evenly distributed in each overlap. An image chip is extracted. At the moment inside this chip the most appropriate location for the tiepoint is chosen, in the way, that the DEM is analyzed for the most flattest region inside the chip as well as for the minimal noise (height error). The final tie-point height will be averaged over e.g. $3 \times 3$ pixel to reduce the noise, although, the noise is partly coloured noise and wont be reducible completely by such a small image size. Therefore, in future studies a tie-point concept will be developed that takes into account larger regions for averaging.

\subsubsection{Functional model}

The constraint of the adjustment is that the heights in overlapping areas should be identical. A function has to be found that expresses this relationship, contains the unknown coefficients $X(a-f)$ and is additionally independent from the absolute terrain height. Against this background height differences are introduced. The observation equation follows the functional description for adjustment with constraints:

$\left[\hat{H}_{i, J}+\hat{g}_{J}(r g, a z)\right]-\left[\hat{H}_{i, K}+\hat{g}_{K}(r g, a z)\right]=0$,

where $\hat{g}(r g, a z)$ is the height error function with the adjusted parameters and $\hat{H}$ is the adjusted elevation value at the tie-points.

Eq. 2 will be set up for each tie-point. Height offsets to WGS84 are estimated by introducing GCPs into the functional model in the same way as observables.

\subsubsection{Stochastical model}

All observables have accuracies that are used as weights for the stochastic model. The cofactor matrix is

$Q_{b b}=\left(\begin{array}{lll}Q_{b b, G C P} & & \\ & Q_{b b, D C P} & \\ & & Q_{b b, T I E}\end{array}\right)$

The cofactor matrix includes the standard deviations for the ground control points (GCP), the corresponding DEM height error of the GCP point (DCP) and the tie-points (TIE).

According to tests the best standard deviation for the GCPs (ICESat points on flat bareland) can not be assumed better than $1.6 \mathrm{~m}$ and usually $2 \mathrm{~m}$. With this accuracy the GCPs fulfil the condition that GCPs should be one order better to influence the adjustment. The standard deviations of the heights are taken from the interferometric height error. A noise level of $2 \mathrm{~m}$ for one single pixel is expected.

In the tests we assume a standard deviation of the absolute ground control points of $2 \mathrm{~m}$. For tie-points we assume not filtered heights with a standard deviation of $2 \mathrm{~m}$, and filtered, i.e. averaged heights with a standard deviation of $0.7 \mathrm{~m}$ and $0.4 \mathrm{~m}$.

\subsection{Iterative adjustment}

The parameters are estimated iteratively. In the first iteration, all 6 parameters are estimated. If the significances

$t=\frac{\hat{x}_{e s t}}{\sigma_{\hat{x}_{\text {est }}}}$,

where $\hat{x}_{\text {est }}$ is the estimated parameter and $\sigma_{\hat{x}_{\text {est }}}$ its standard deviation, of all parameters for one data take are not smaller than a given value ( $t>=1$ in the tests), the parameters are accepted. If not, the adjustment is computed again, no longer estimating the parameters with the smallest significance. 


\section{ADJUSTMENT RESULTS ON SIMULATED DATA}

The proposed block adjustment is evaluated on simulated distorted DEM data. For this task, heights of a test area of $3 \times 4$ data takes (each $30 \times 500 \mathrm{~km}$ wide) were simulated with noise and errors as described in Eq. 1. Also, the coverage in the second year was simulated (see Figure 1).
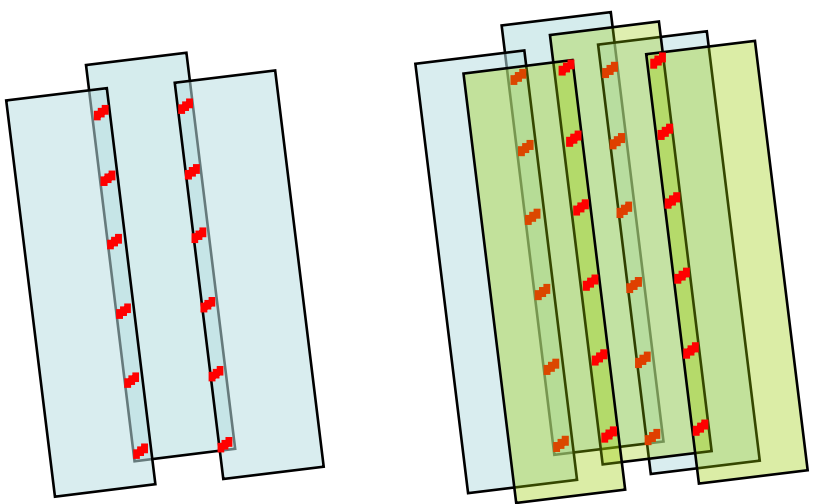

Figure 1: In blue the first coverage, in blue and green the first and second coverage. The second coverage is shifted by the half of the data takes width. In red: tie-points.

In our simulations the following parameters were varied:

- the noise of the tie-points $(0.4 \mathrm{~m}, 2 \mathrm{~m})$,

- the distance between two adjacent ICESat ground tracks in across track (at the equator $80 \mathrm{~km}$, in temperate zones $55 \mathrm{~km}$, and at the pole $15 \mathrm{~km}$ ),

- the distance between ICESat points in flight direction $(1000 \mathrm{~km}, 100 \mathrm{~km}, 10 \mathrm{~km})$,

- $\quad$ the number of simulated parameters $(1,3,6)$,

- $\quad$ and the distance between the tie-points.

\begin{tabular}{|l|l|l|l|}
\hline & EQUA & TMPZ & POLE \\
\hline $\mathbf{1 0 0 0} \mathbf{~ k m}$ & 0.8 & 1.6 & 8 \\
\hline $\mathbf{1 0 0} \mathbf{~ k m}$ & 8 & 11 & 46 \\
\hline $\mathbf{1 0} \mathbf{~ k m}$ & 77 & 108 & 440 \\
\hline
\end{tabular}

Table 1: Number of ICESat points per data take. The columns stand for the different regions (equator, temperate zone and pole) respectively to the different GCP distances in across-track (80km, $55 \mathrm{~km}$ and $15 \mathrm{~km}$ ), the rows for the distance between ICESat points in flight direction $(1000 \mathrm{~km}, 100 \mathrm{~km}$ and $10 \mathrm{~km})$.

The distance between a tie-point triple in range is $5 \mathrm{~km}$ in azimuth. The noise of the ground control points is set to 2 $\mathrm{m}$. The first and second year coverage is adjusted first separately and then also together.

For each of the configurations listed above the leastsquares adjustment described in Ch. 2 is carried out. In order to check, if the parameter model is estimated correctly, the differences between the initially simulated and the resultant estimated height error function are calculated:

$$
\Delta H_{\max }=\max \left(g_{\text {sim }}(r g, a z)-\hat{g}_{\text {est }}(r g, a z)\right)
$$

where $\quad g_{\text {sim }}=$ simulated height error function

$\hat{g}_{\text {est }}=$ estimated height error function.

In order to ensure to fulfil the relative accuracy of $2 \mathrm{~m}$, the maximum height difference $\Delta \mathrm{H}_{\max }$ should not be higher than $1 \mathrm{~m}$. The maximum of $g_{\text {sim }}$ is $2 \mathrm{~m}$ compared to the undistorted DEM.

The Tables below show the results of different test configurations. The columns show the three different regions (equator, temperate zone and pole) and are subdivided into another two columns describing the different noise levels of the tie-points $(0.4 \mathrm{~m}$ and $2.0 \mathrm{~m})$. The rows show the distance between the ICESat points in flight direction $(1000 \mathrm{~km}, 100 \mathrm{~km}$ and $10 \mathrm{~km})$. They are also subdivided into another three rows, describing the number of simulated parameters (a, abc and abcdef). The first row and the first column of the second row include the results of the worst configurations, including less than 10 ground control points per data take (see Table 1). These configurations will only appear in very difficult areas, e.g. in rain forests and high mountains. Most of the areas will contain at least 400 ICESat points or even more.

\subsection{Results for varying noise, simulated parameters, number of GCPs and tie-points}

Table 2 shows the maximum height differences averaged over all data takes. The estimated parameter set (whose significances lie under 1) is approved, if the maximum height difference (described in Eq. 6) is smaller or equal $1 \mathrm{~m}$. Is the absolute mean smaller or equal $0.5 \mathrm{~m}$ and $1 \mathrm{~m}$ respectively, the value is indicated with dark and light blue respectively. Especially for the best configurations (POLE/10km, POLE/100km, TMPZ/10km, EQUA/10km), it shows that the results are near to $1 \mathrm{~m}$ difference. Note, that in these tests, first and second year were adjusted together, i.e. the number of tie-points was higher.

Note, that the criterion for the acceptance of the parameter set is $1 \mathrm{~m}$, whereas the simulated height error is $2 \mathrm{~m}$. That means, that the height model is often improved, even though the parameter set is not approved. Otherwise in regions with less than one ground control point per data

\begin{tabular}{|cc|rr|rr|rr|}
\hline dist. of GCP & sim. & \multicolumn{2}{|c|}{ EQUA } & \multicolumn{2}{|c|}{ TMPZ } & \multicolumn{2}{|c|}{ POLE } \\
along-track & par. & $\sigma=0.4 m$ & $\sigma=2.0 \mathrm{~m}$ & $\sigma=0.4 m$ & $\sigma=2.0 \mathrm{~m}$ & $\sigma=0.4 m$ & $\sigma=2.0 \mathrm{~m}$ \\
\hline \multirow{3}{*}{$1000 \mathrm{~km}$} & a & 0.62 & 0.64 & 0.29 & 0.56 & 0.52 & 0.61 \\
& abc & 1.45 & 1.72 & 1.45 & 1.40 & 1.68 & 1.35 \\
& abcdef & 2.01 & 2.63 & 1.78 & 1.97 & 1.31 & 1.47 \\
\hline \multirow{3}{*}{$100 \mathrm{~km}$} & a & $\mathbf{0 . 3 8}$ & 0.84 & 0.67 & 0.59 & 0.79 & 0.80 \\
& abc & 1.20 & 1.22 & 1.16 & 1.31 & 1.07 & 1.24 \\
& abcdef & 1.50 & 1.60 & 1.56 & 1.62 & 0.93 & 1.21 \\
\hline \multirow{2}{*}{$10 \mathrm{~km}$} & a & 0.74 & $\mathbf{0 . 4 9}$ & 0.61 & 0.76 & 0.89 & 0.98 \\
& abc & 1.05 & 1.10 & 0.83 & 0.94 & 0.93 & 1.14 \\
& abcdef & 1.11 & 1.22 & 1.01 & 1.07 & 1.08 & 1.19 \\
\hline
\end{tabular}

Table 2: Absolute mean of maximum height differences of all data takes. 


\begin{tabular}{|c|c|c|c|c|c|c|c|}
\hline \multirow{2}{*}{$\begin{array}{c}\text { dist. of GCP } \\
\text { along-track }\end{array}$} & \multirow{2}{*}{$\begin{array}{l}\text { sim. } \\
\text { par. }\end{array}$} & \multicolumn{2}{|c|}{ EQUA } & \multicolumn{2}{|c|}{ TMPZ } & \multicolumn{2}{|c|}{ POLE } \\
\hline & & $\sigma=0.4 m$ & $\sigma=2.0 \mathrm{~m}$ & $\sigma=0.4 \mathrm{~m}$ & $\sigma=2.0 \mathrm{~m}$ & $\sigma=0.4 \mathrm{~m}$ & $\sigma=2.0 \mathrm{~m}$ \\
\hline \multirow{3}{*}{$1000 \mathrm{~km}$} & a & -0.91 & -0.11 & 0.13 & -0.07 & -010.67 & 0.13 \\
\hline & abc & -1.31 & -0.24 & -0.22 & -0.41 & 0.48 & 0.21 \\
\hline & abcdef & -0.600 & 0.70 & -0.22 & -0.25 & -0.70 & -0.22 \\
\hline \multirow{3}{*}{$100 \mathrm{~km}$} & a & -2.04 & -0.05 & -0.01 & 0.08 & 0.14 & 0.04 \\
\hline & abc & -40.68 & $-0,47$ & -0.00 & 0.01 & $-0,08$ & 0.17 \\
\hline & abcdef & $-0,21$ & -0.02 & 0.26 & 0.03 & -0.20 & -0.04 \\
\hline \multirow{3}{*}{$10 \mathrm{~km}$} & a & -0.53 & -0.33 & -0.28 & 0.03 & -0.07 & -0.04 \\
\hline & abc & -0.18 & -0.12 & -0.11 & -0.13 & -0.09 & -0.01 \\
\hline & abcdef & -0.03 & -0.13 & -0.13 & -0.09 & -0.09 & -0.01 \\
\hline
\end{tabular}

Table 3: Difference of absolute mean between adjustment with and without tie-point triple

take, the heights can be worsen as the maximum height difference is sometimes greater than $2 \mathrm{~m}$.

To estimate a higher number of parameters, at least 40 ground control points per data take should be available. In this case the absolute mean is about $1 \mathrm{~m}$ or less. Note, if only two ground control points per data take or less are available, only one parameter can be estimated. Therefore, if only the offset is simulated, the results are better in areas with few ground control points. Using a greater number of ground control points, often more than one parameter is estimated significantly, even though only the offset is simulated. This shows a limitation of the adjustment approach, if the height errors are in the same order like the noise, the results are randomly too.

In order to evaluate, if one tie-point instead of a tie-point triple (see Figure 1) is enough, Table 3 was created. It shows the difference of the absolute mean between the adjustment with and without tie-point triples. In areas with few ground control points, it is better to use the tie-point triple, in areas with many ground control points, the adjustment with the tie-point triple improves the results less.

\subsection{Results for combined adjustment of $1^{\text {st }}$ and $2^{\text {nd }}$ coverage}

Table 4 shows the difference between combined (first and second year adjusted together) and separate solution (first and second year adjusted separately). Adjusting first and second year together improves the results considerably,

\begin{tabular}{|c|c|c|c|c|c|c|c|}
\hline \multirow{2}{*}{$\begin{array}{l}\text { dist. of GCP } \\
\text { along-track }\end{array}$} & \multirow{2}{*}{$\begin{array}{l}\text { sim. } \\
\text { par. }\end{array}$} & \multicolumn{2}{|c|}{ EQUA } & \multicolumn{2}{|c|}{ TMPZ } & \multicolumn{2}{|c|}{ POLE } \\
\hline & & $\sigma=0.4 \mathrm{~m}$ & $\sigma=2.0 \mathrm{~m}$ & $\sigma=0.4 \mathrm{~m}$ & $\sigma=2.0 \mathrm{~m}$ & $\sigma=0.4 m$ & $\sigma=2.0 \mathrm{~m}$ \\
\hline \multirow{3}{*}{$1000 \mathrm{~km}$} & a & -0.74 & -1.32 & -0.41 & -0.07 & -0.50 & 0.02 \\
\hline & $a b c$ & $-0.98 \mathrm{~s} x-3$ & -0.14 & -0.03 & -0.20 & 0.05 & -0.09 \\
\hline & abcdef & -1.34 & -1.80 & 0.01 & -0.04 & -0.05 & -0.2. \\
\hline \multirow{3}{*}{$100 \mathrm{~km}$} & a & -0.47 & -0.19 & -0.29 & 0.13 & 0.12 & 0.06 \\
\hline & abc & -0.21 & -0.08 & 0.05 & -0.25 & 0.07 & 0.06 \\
\hline & abcdef & -0.11 & -0.43 & 0.03 & -0.17 & -0.30 & -0.01 \\
\hline \multirow{3}{*}{$10 \mathrm{~km}$} & a & -0.20 & -0.03 & -0.07 & -0.03 & 0.09 & 0.14 \\
\hline & abc & 0.19 & -0.02 & -0.17 & -0.04 & 0.12 & 0.14 \\
\hline & abcdef & -0.14 & $-0,08$ & -0.15 & -0.18 & -0.07 & 0.04 \\
\hline
\end{tabular}

Table 4: Difference of absolute mean between combined and separated adjustment. mainly in areas with few ICESat points. This is up to the higher number of tie-points and the higher constraints between the data takes. However, in most areas (containing at least 400 ground control points) the results cannot be improved by a combined adjustment.

\section{CONCLUSIONS}

In this paper an approach for height adjustment of interferometric DEMs for the TanDEM-X mission is proposed. For each DEM several error parameters are estimated within a block adjustment. The difficulty is that the magnitude of the errors is in the same order like the noise of the tie-points and the accuracy of the ground control points $(2 \mathrm{~m})$. Therefore, tests with different configurations have been carried out to evaluate the reliability of the adjustment. It can be stated that the offset could be estimated in all scenarios with an accuracy of $1 \mathrm{~m}$ and better. For higher order parameters like the tilts, the results improve with increasing number of GCPs. Luckily, the necessary amount of GCPs will be present for most regions of the world. A combined adjustment of the first and the second coverage improves especially the results with less GCPs and has less influence of the good conditioned cases as expected. Further studies will be made regarding a new tie-point averaging concept that will probably achieve better standard deviations.

\section{ACKNOWLEDGMENTS}

The TanDEM-X project is partly funded by the German Federal Ministry for Economics and Technology (Förderkennzeichen 50 EE 0601).

\section{REFERENCES}

[1] Huber, M., Wessel, B., Kosmann, D., Felbier, A., Schwieger, V., Habermeyer, M., Wendleder, A., and Roth, A., 2009. Ensuring globally the TanDEM-X height accuracy: Analysis of the reference data sets ICESat, SRTM, and KGPS-Tracks. In: Proceedings of IGARSS 2009, Cape Town, South Africa, in print.

[2] G. Krieger, A. Moreira, H. Fiedler, I. Hajnsek, M. Werner, M. Younis, M. Zink, M., 2007. TanDEM-X: A Satellite Formation for High Resolution SAR Interferometry. Transactions on Geoscience and Remote Sensing, 45(11), pp. 3317-3341.

[3] Wessel, B., Marschalk, U., Gruber, A., Huber, M., Hahmann, T., Roth, A., Habermeyer, M., Kosmann, D., 2008. Design of the DEM Mosaicking and Calibration Processor for TanDEM-X. In: Proc. of EUSAR 2008, Friedrichshafen, Germany, Vol. 4, pp. 111114.

[4] Zwally, J., 2002. ICESat's laser measurements of polar, ice, atmosphere, ocean, and land. Journal of Geodynamics, 34, pp. 405-445. 